\title{
Environmental analysis of Nanjing Mosque courtyard layout based on CFD simulation technology
}

\author{
Wael Alhasan ${ }^{1 *}$, Cheng Yuning ${ }^{2}$ \\ ${ }^{1}$ Architecture, Southeast University, Nanjing, Jiangsu, 210096, China \\ ${ }^{2}$ Architecture Engineering, Tishreen, Latakia, Latakia, Syria
}

\begin{abstract}
Courtyards are claimed to be extremely effective in improving the freshening and decreasing the humidity level, also showed a strong correlation between courtyard wall surface temperatures. The article aims to evaluate the thermal effects of a Mosque courtyard quantitatively and to suggest guidelines to design more sustainable built environments in the climate zone. In this part, Chinese Mosques in Nanjing city with different layouts and weather conditions were analyzed. The Mosque climate design discussed in this study is temperature and wind velocity. Briefly, the main essence is to clarify the differences between different Mosque layouts and to determine if the feature of courtyard orientation would make this Mosque style efficient.
\end{abstract}

\section{Introduction}

Since Islam with its long course of historical development was introduced into China in the mid-seventh century, Islamic culture premise of adhering to its core doctrines, the ordinary of value, it engages factors and expressions favourable to its own development, and changes it reasonably, to adapt to the local social and cultural environment [1]. Accelerated the process of the nationalization of Islam in China, making Islam, a religion coming from the outside world, not only root profoundly in China but also mingled with traditional Chinese culture, it had taken on obvious characteristics of traditional Chinese culture, whether in the form of presentation or deep-seated doctrine and ethics [2]. As for the Mosque courtyard components, it developed in an attempt to assimilate culture into Chinese style or traditional forms and techniques as a result of response the cultural needs[]ㅡ. Whenever and wherever Muslims first entered China, the Mosque architecture was already a coherent system that had been governed by principles. The most important one is buildings formed around enclosed courtyards. This courtyard is an enclosed outdoor space, ordinarily open to the elements at the top; it does not have a definitive plan. The primary design of a courtyard is typically rectangular or square, the form changing to accommodate ecological and cultural aspects. The scale and size of Chinese Mosque courtyards range from very small to expansive depending on its use. As for function and elements of each courtyard, it varies by region or style [4].

The impact of courtyards in some climates has been evaluated qualitatively and quantitatively by using field measurements and computer modeling [5-10] However, and there have been very few studies that focus on the different climate where, due to the utilization of courtyards merits detailed investigations $[\underline{8}, \underline{11}, \underline{12}]$. In recent years, there has been a growing interest in the design of courtyards for the microclimatic enhancement of outdoor spaces. However, there is still little knowledge regarding the thermal performance characteristics of courtyards, particularly in China. Environment affects how users sense to a high temperature; therefore, significance should be linked to it in building scheme. CFD simulation technology not only gives suitability to architects but also exposes an innovative part in the scheme where CFD environment simulation and architectural scheme approach are put together. With the CFD environment simulation technology, architects can enhanced scheme and more define the environment in design, and conduct the examination based on related building technologies and simulation outcomes, in a way to offer more source for evaluation and show quantification of surroundings design [13]. This study evaluates the ability of courtyards for providing thermally comfortable outdoor spaces according to different design configurations and scenarios, including the orientations, height and use of its physical and natural elements. Therefore, this study aims to highlight this important aspect of Mosque courtyard design. Because this type of buildings courtyard possesses are of high importance and respect in urban societies, as well as other religious buildings. As a result, it is possible to benefit from this symbolism to increase public awareness of the importance of environment conservation and energy-saving issues and mentions to design methods that simplify the natural ventilation and the use of renewable vitalities through the architectural elements (site and plan design) $[14,15]$. As a result, scheme responds to the natural perspective, while it is also affected and confined by the geographical

*Corresponding author's e-mail: wael_alhasan2008@yahoo.com 
environments therefore is obviously local- and climaticadaptive[16, 17].

\section{Courtyard thermal effects}

A courtyard is an enclosed outdoor or semi-outdoor space surrounded by buildings and open to the sky. Courtyards were primarily adopted in vernacular buildings in parts of Asia, the Middle East, South America, and the Mediterranean countries [18-20]. Different models have been adopted for courtyards design in different countries with different weathers, through the centuries. Arabs often use it especially in house, Mosques and palaces. As for Chinese, Courtyards were similarly observed in the design of Chinese traditional home, temple and palace [21]. The growing interest in the use of courtyards in various types of contemporary architectural projects including residential, educational, healthcare and Mosques, so their function was to improve comfort conditions by modifying the microclimate around the building and by improving ventilation. The impact of courtyards in some climates has been evaluated qualitatively and quantitatively by using field measurements and computer modeling [5-10] However, and there have been very few studies that focus on the different climate where due to the utilization of courtyards merits detailed investigations. $[\underline{8}, \underline{11}, \underline{12}]$

\subsection{Mosque courtyard thermal effects}

Islamic architecture starts with Mosque not because the Mosque has been the first construction built by Moslems in Medina and by the guidance of the Prophet, but because it has gathered all of the architecture functions in itself. Mosque has been not only a place for praying but also a center for managing all the affairs that had a direct or indirect relationship with religion. Mosque courtyard acquires its importance from being the main spiritual center for Muslims. Hundreds of thousands of Mosques have been built to serve Muslims across the world. Also, it resulted in a wide diversity of design criteria, where different architectural courtyard elements and styles could be distinguished.

Many designs nowadays, started to reclaim a more comprehensive role of the contemporary Mosque as a multi-purpose building. Designs are implemented by the use of many facilities attached to the prayer hall to meet social needs, mainly for welfare. The designs highlight the importance of investigating the courtyard thermal performance of this building type to ensure that its users are thermally comfortable. Although many studies had focused on Mosque courtyard design, few of them discussed the environmental aspects of this design. For example, the research found that it is possible to significantly reduce the cooling load of air-conditioned Mosques by utilizing adequate passive means [22]. Another study investigated the climatic conditions, they found that Mosque courtyard can be used as prayer zone for a period up to $32 \%$ of the overheated period of the year, also recommended additional examination of the courtyard thermal potential in Mosques [23].

The building of a Mosque currently is a great achievement of the Muslim community, particularly if the community is living in a non-Muslim country. Technology has been the drive to improve construction method of the early Muslim community that influence of values and perception towards Islam in the whole world until today. While appreciating the quantitative increase and aesthetic embellishments of many new Mosques design, several Muslim scholars, intellectuals and activists have expressed their concern and reservation regarding the function of these Mosques.

\section{Design schemes of Nanjing city mosque}

Islam was tolerated, missionaries from Central Asia and Arabia made their way into China, especially Nanjing the first Ming capital which was called Jiankang. The Muslims population in Nanjing increased as a result and became the city where Muslims lived most intensively on the southeast coast of China and celebrated as a center of Islamic learning and culture $[\underline{2}, \underline{24}]$. The sub-provincial city of Nanjing is divided into 11 districts; there are 12 Mosques in it. The Jingjue Mosque is the ancient Mosque still existence in Nanjing today; it was built in the Ming Dynasty (1368-1398 A.D) [2]. Like other seven ancient Mosques in the city has been restored and new buildings have been added to it during different periods. As for modern Mosques, it is four Mosques, two of which have been completed and one is still under construction and the last one just proposed 'figure 1'. 


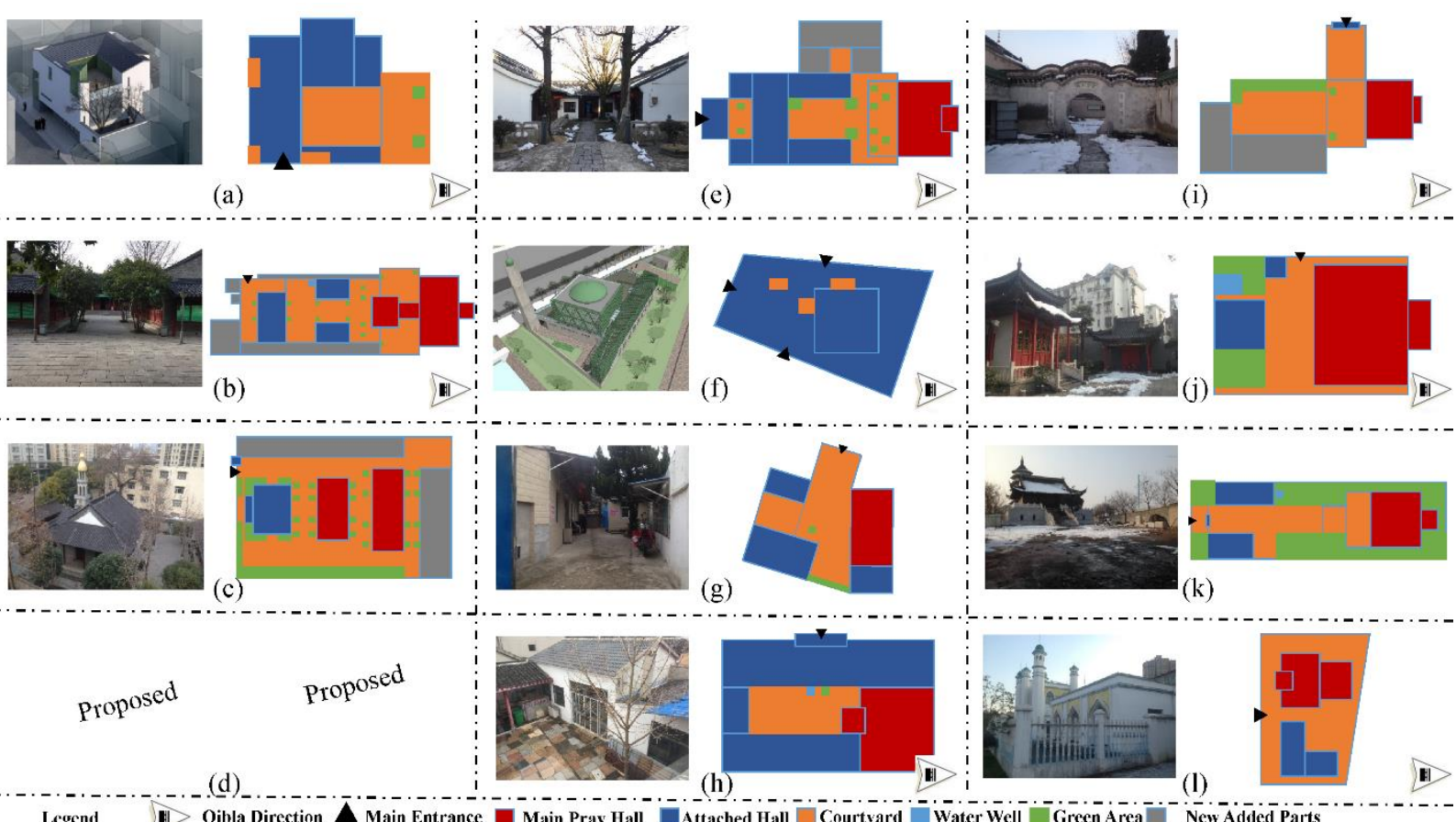

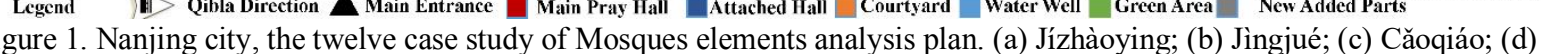

Tàipínglù; (e) Húshú; (f) Dōngmén; (g) Yītiáoxiàng; (h) Xīngdiàn; (i) Zhúzhn; (j) Chángjiāng; (k) Nánmén; (l) Lìshuǐ.

\section{Methodology}

It is considering that the architectural style of the Mosques in China came similar to that of the traditional Chinese house and in keeping with each region local culture and climatic conditions without being influenced by the cultures of Islamic civilization in the neighboring countries. Nanjing city Mosque as Chinese Mosque style was climatically analyzed with the Arabic one using the Sketch-Up and Phoenics program as a way to understand the importance of Mosque layout style in increasing the effectiveness of harmony between design and surrounding climatic environment.

After the three-dimensional creation of all mosques in the city using the Sketch Up program 'figure 2', all the models were imported into the environmental analysis program Phoenics 2019. All the climatic information for Nanjing city was used in EPW files format which downloaded from the World Climate Database (Energy +). The climatic conditions were then applied to all study cases as a means of testing the environmental efficiency of the mosque inner courtyard space (thermal, wind speed). Note that analyses were conducted for extreme temperatures (15th July).

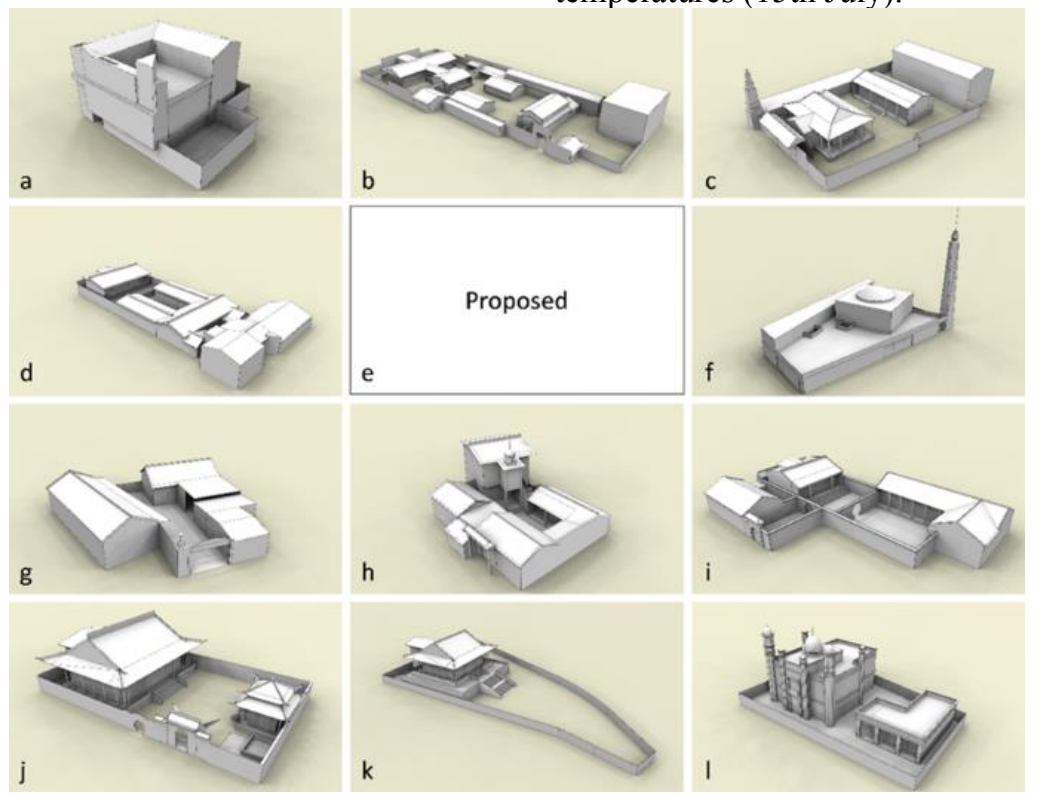

Figure 2. 3D models for the eleven Mosque case study in Nanjing city. (a) Jízhàoying; (b) Jìngjué; (c) Căoqiáo; (d) Tàipínglù; (e) Húshú; (f) Dōngmén; (g) Yītiáoxiàng; (h) Xīngdiàn; (i) Zhúzhn; (j) Chángjiāng; (k) Nánmén; (l) Lìshuǐ. 


\section{Result and Discussion}

Whether in Chinese or Arabic civilization, the inner courtyard is one of the most ancient elements in the design of Mosques. Besides, the existence of cultural differences and civilization in the city of Nanjing between foreign Muslims and Chinese. In order to highlight the Mosque courtyard layout environmental potential, an exploratory thermal modeling study carried out. The climate analysis will be prepared by applying computerized thermal performance layout modeling using Phoenics 2018 and Sketch-Up program. That software used in building design and environmental analysis tool that offers several
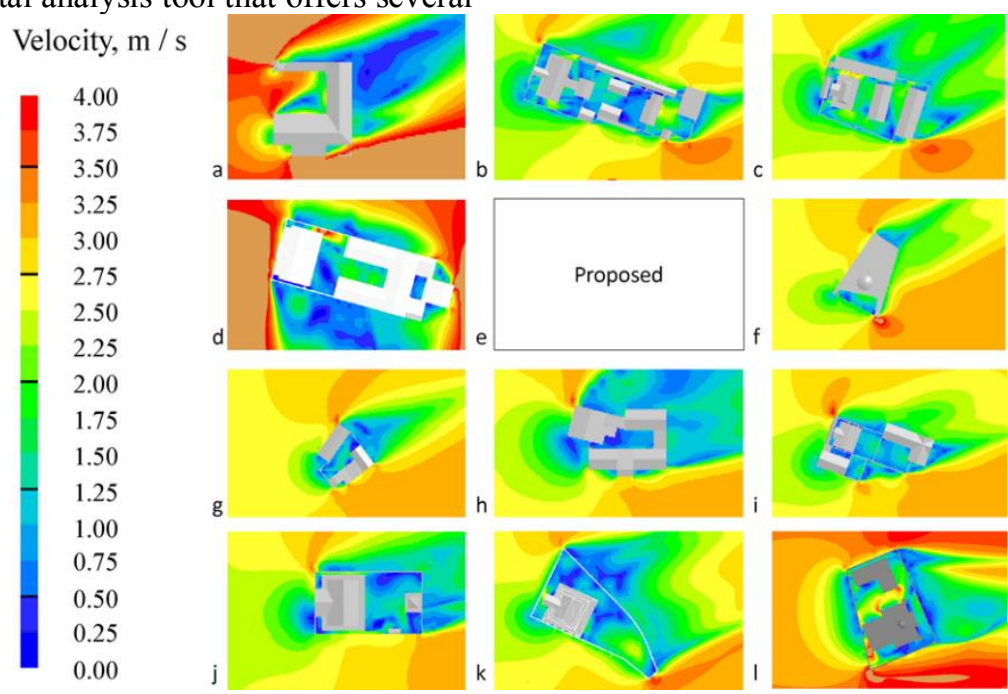

analysis functions to show how buildings operate thermally. It allows for two and three-dimensional modeling of buildings considering many variables like geographical location, building design and materials, ventilation, weather EPW data, temperature and lighting systems, etc.

Analytical charts of wind velocity simulation show that the courtyards in the traditional Chinese- Mosques style achieved a high level of wind speed mitigation where the speed ranged between 0.00-1.75 meters/second. In other words, the level of user environmental and thermal comfort in terms of wind velocity within these courtyards is very high 'figure 3 '.

Figure 3. CHAM - Phoenics wind velocity CFD simulation for Nanjing city Mosque, (a) Jízhàoying; (b) Jìngjué; (c) Căoqiáo; (d)

Tàipínglù; (e) Húshú; (f) Dōngmén; (g) Yītiáoxiàng; (h) Xīngdiàn; (i) Zhúzhn; (j) Chángjiāng; (k) Nánmén; (l) Lìshuǐ.

On the other hand, Environmental comfort within the inner courtyard of the Mosque declined in reverse with the opening of the courtyard towards the south and south-west, as we see in the case (c, f, k), where the wind velocity reached 2.5 meters / second. As for the highest wind velocity, it was observed in the study case (a), where the inner courtyard was fully open to the west (wind velocity reach 7 meters/second) 'figure 3'. The position of the inner courtyard also plays a large role in increasing the velocity of the wind affecting it as seen in example 'figure 3. a', where the courtyard is located on the third floor, unlike other examples.

In the case of environmental comfort caused by temperatures inside the courtyard, the gradual decrease in temperature was observed and thus increased environmental comfort in the courtyard from the courtyard south-west side to the northeast side (from 51to $39{ }^{\circ} \mathrm{C}$ ). Also, temperatures increased on the southwestern edge of the yard whenever the rib was more open, or there were no architectural blocks (temperature reach $57^{\circ} \mathrm{C}$ ) as we see in case (b, c, i, k). As for the open courtyard from the west side, it has achieved high efficiency of thermal comfort design (case a), the temperature was ranging between 29 and $37^{\circ} \mathrm{C}$ 'figure 4 '. 


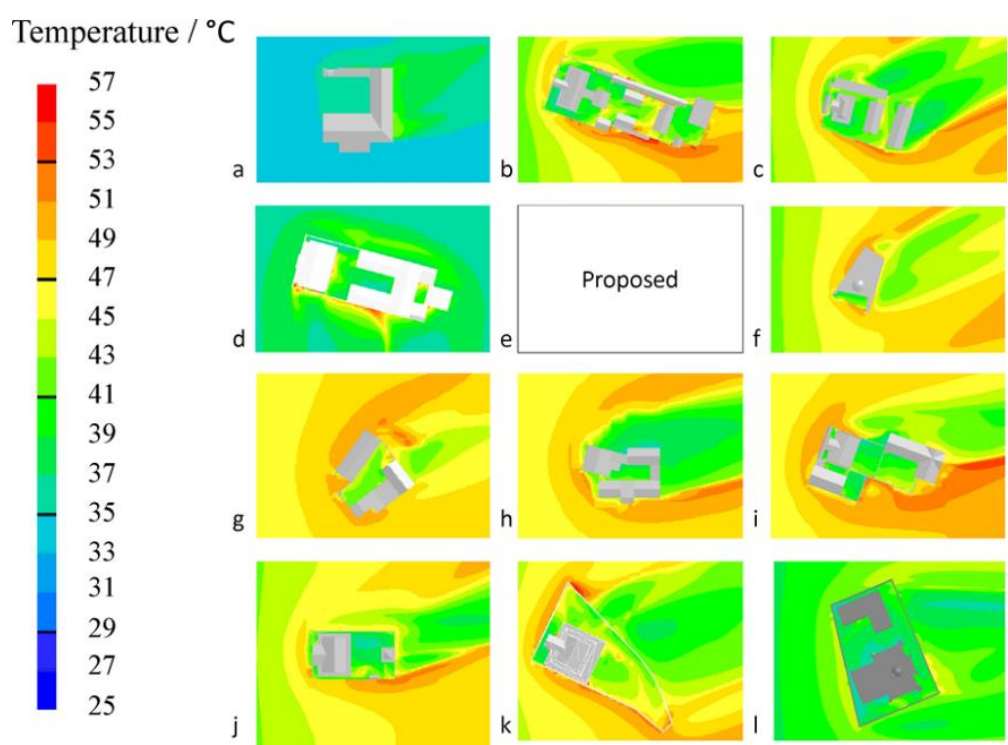

Figure 4. CHAM - Phoenics temperature CFD simulation for Nanjing city Mosque, (a) Jízhàoying; (b) Jìngjué; (c) Căoqiáo; (d) Tàipínglù; (e) Húshú; (f) Dōngmén; (g) Ȳitiáoxiàng; (h) Xīngdiàn; (i) Zhúzhn; (j) Chángjiāng; (k) Nánmén; (l) Lìshuľ.

\section{Conclusion}

The findings show, the traditional Chinese Mosque closed three- or four-side model (Sanheyuan, Siheyuan) achieves high environmental efficiency, both in terms of handling wind velocity and temperature. In general, the opening of the Mosque courtyard space to the west in Nanjing city is a design style that must be avoided or manipulated using natural or physical elements that are thoughtfully designed to reduce the speed of the wind inside the courtyard. As for the opening of the courtyard on the south and southwest, it represents a better design style than the opening to the West, in addition to the use of plant elements that distributed within the courtyard will contribute in reducing the temperature resulting from this openness in the vicinity of these two-way areas. Accordingly, the four directions of the model achieve high environmental efficiency both in terms of dealing with wind and temperatures.

\section{Reference}

1. Junqing, M. (2013) The Present Situation and Characteristics of Contemporary Islam in China. Doshisha University Center for Interdisciplinary Study of Monotheistic Religions (CISMOR)., 8: 2636.

2. Mi, S., You, J., Min, C. (2004) Islam in China. China Intercontinental Press, Beijing.

3. Qiu, Y., Sun, D. (2003) Islamic buildings. Springer-Verlag, Wien; New York.

4. Meir, I. (2000) Courtyard microclimate: A hot arid region case study. In: Architecture City Environment, Proceedings of the 17th PLEA International Conference. Cambridge, James \& James, London. pp. 218-223.

5. Berkovic, S., Abraham, Y., Arieh, B. (2012) Study of thermal comfort in courtyards in a hot arid climate. Solar Energy., 86: 1173-1186
6. Safarzadeh, H., Bahadori, M. (2005) Passive cooling effects of courtyards. Building and Environment., 40(1): 89-104

7. Muhaisen, A.S., Gadi, M.B. (2006) Shading performance of polygonal courtyard forms., 41(8): 1050-1059

8. Shashua-Bar, L., Pearlmutter, D., Erell, E. (2009) Microscale vegetation effects on outdoor thermal comfort in a hot-arid environment. In: Proc. of the seventh international conference on urban climate. Yokohama, Japan. Vol 29.

9. Acosta, I., Navarro, J., Sendra, J.J. (2013) Predictive method of the sky component in a courtyard under overcast sky conditions., 89: 8999

10. Taleghani, M., Sailor, D.J, Tenpierik, M, van den Dobbelsteen, A. (2014) Thermal assessment of heat mitigation strategies: The case of Portland State University, Oregon, USA. Building and Environment., 73: 138-150

11. Rajapaksha, I., Nagai, H., Okumiya, M. (2003) A ventilated courtyard as a passive cooling strategy in the warm humid tropics., 28(11): 1755-1778

12. Sadafi, N., Salleh, E., Haw, L.C.,Jaafar, Z. (2011) Evaluating thermal effects of internal courtyard in a tropical terrace house by computational simulation., 43(4): 887-893

13. Murakami, S. (2007) CFD and building environment design. China Architecture \& Building Press, Beijing.

14. Givoni, B. (1994) Passive low energy cooling of buildings. John Wiley \& Sons.

15. Givoni, B. (1998) Climate considerations in building and urban design. John Wiley \& Sons.

16. Yang, L., Lam, J.C., Liu, J. (2005) Bioclimatic building designs for different climates in China., 48(2): 187-194. 
17. John, G., Clements-Croome, D., Jeronimidis, G. (2005) Sustainable building solutions: a review of lessons from the natural world., 40(3): 319-328.

18. Khan, N., Su, Y., Riffat, S.B. (2008) A review on wind driven ventilation techniques., 40(8): 15861604.

19. Al-Masri, N., Abu-Hijleh, B. (2012) Courtyard housing in midrise buildings: An environmental assessment in hot-arid climate., 16(4): 1892-1898

20. Berardi, U., Wang, T. (2014) Daylighting in an atrium-type high performance house., 67: 92-104.

21. Kubota, T., Toe, D.H.C., Ossen, D.R. (2014) Field investigation of indoor thermal environments in traditional Chinese shophouses with courtyards in Malacca., 13(1): 247-254.

22. The Nanjing Islamic Association. (2017) Entering the mosque. http://www.njislam.com/zjqzs.asp.

23. Al-Najim, A., Al-Mofeez, I. (1999) The Role of Courtyard in Power Consumption of the Mosque. Eben Saleh, M., Alkokani. In: Proceedings of the symposium on mosque architecture. pp. 1-12.

24. Dillon, M. (2001) China's Islamic frontiers: Borders and identities. Boundary and Security Bulletin., 8(4): 97-104. 